\title{
Quantitative Computed Tomography (QCT) derived Bone Mineral Density (BMD) in finite element studies: a review of the literature
}

Nikolas K. Knowles ${ }^{1,2,3^{*}}$, Jacob M. Reeves ${ }^{2,3,4}$ and Louis M. Ferreira ${ }^{1,2,3}$

\begin{abstract}
Background: Finite element modeling of human bone provides a powerful tool to evaluate a wide variety of outcomes in a highly repeatable and parametric manner. These models are most often derived from computed tomography data, with mechanical properties related to bone mineral density (BMD) from the $x$-ray energy attenuation provided from this data. To increase accuracy, many researchers report the use of quantitative computed tomography $(\mathrm{QCT})$, in which a calibration phantom is used during image acquisition to improve the estimation of BMD. Since model accuracy is dependent on the methods used in the calculation of BMD and density-mechanical property relationships, it is important to use relationships developed for the same anatomical location and using the same scanner settings, as these may impact model accuracy. The purpose of this literature review is to report the relationships used in the conversion of QCT equivalent density measures to ash, apparent, and/or tissue densities in recent finite element (FE) studies used in common density-modulus relationships. For studies reporting experimental validation, the validation metrics and results are presented.

Results: Of the studies reviewed, $29 \%$ reported the use of a dipotassium phosphate $\left(\mathrm{K}_{2} \mathrm{HPO}_{4}\right)$ phantom, $47 \%$ a hydroxyapatite (HA) phantom, 13\% did not report phantom type, 7\% reported use of both $\mathrm{K}_{2} \mathrm{HPO}_{4}$ and $\mathrm{HA}$ phantoms, and $4 \%$ alternate phantom types. Scanner type and/or settings were omitted or partially reported in $31 \%$ of studies. The majority of studies used densitometric and/or density-modulus relationships derived from different anatomical locations scanned in different scanners with different scanner settings. The methods used to derive various densitometric relationships are reported and recommendations are provided toward the standardization of reporting metrics.

Conclusions: This review assessed the current state of QCT-based FE modeling with use of clinical scanners. It was found that previously developed densitometric relationships vary by anatomical location, scanner type and settings. Reporting of all parameters used when referring to previously developed relationships, or in the development of new relationships, may increase the accuracy and repeatability of future FE models.
\end{abstract}

Keywords: QCT, Bone density, Finite element analysis, Mechanical properties

\footnotetext{
* Correspondence: nknowle@uwo.ca

${ }^{1}$ Graduate Program in Biomedical Engineering, The University of Western

Ontario, 1151 Richmond St, London, ON, Canada

${ }^{2}$ Roth|McFarlane Hand and Upper Limb Centre, Surgical Mechatronics

Laboratory, St. Josephs Health Care, 268 Grosvenor St, London, ON, Canada

Full list of author information is available at the end of the article
}

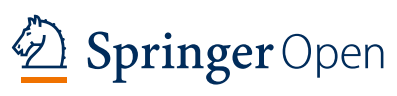

(c) The Author(s). 2016 Open Access This article is distributed under the terms of the Creative Commons Attribution 4.0 International License (http://creativecommons.org/licenses/by/4.0/), which permits unrestricted use, distribution, and reproduction in any medium, provided you give appropriate credit to the original author(s) and the source, provide a link to the Creative Commons license, and indicate if changes were made. 


\section{Background}

Accurate characterization of the properties of bone in finite element (FE) studies, including accurate local bone density (Schileo et al. 2008; Synek et al. 2015), is essential to improve the accuracy of existing continuum-level FE modeling techniques (Schileo et al. 2008). Uncalibrated clinical CT images are limited to voxel information in the form of $\mathrm{x}$-ray absorption coefficients, using the Hounsfield (HU) scale, with air $(-1000 \mathrm{HU})$ and water $(0 \mathrm{HU})$ as references. For high atomic number materials, quantitative computed tomography (QCT) provides local densitometric measurements in volumetric bone mineral density (vBMD) (Engelke et al. 2013). This allows for accurate regional variations in BMD to be mapped in subsequent continuum-level finite element models (FEMs). The accuracy and characterization of using calibration phantoms has been well established over the past two decades (Faulkner et al. 1993; Keyak et al. 1994; Les et al. 1994; Schileo et al. 2008).

Calibrated vBMD or quantitative equivalent CT density ( $\left.\rho_{\mathrm{QCT}}\right)$ is calculated by measuring the CT scanner's response to the phantom's calibrated regions. Typical calibration phantoms contain rods with varying concentrations of calcium hydroxyapatite (HA) (Engelke et al. 2013; Poelert et al. 2013), or are calibrated using liquid dipotassium phosphate $\left(\mathrm{K}_{2} \mathrm{HPO}_{4}\right)$, and provide equivalent density in units of $\mathrm{mg}_{\mathrm{HA}} / \mathrm{cm}^{3}\left(\rho_{\mathrm{HA}}\right)$ or $\mathrm{mg}_{\mathrm{K}_{2} \mathrm{HPO}_{4}} / \mathrm{cm}^{3}\left(\rho_{\mathrm{K}_{2} \mathrm{HPO}_{4}}\right)$ (Keyak et al. 1994; Les et al. 1994). These imaging based density methods have been related to physical methods, such as ash density (ash mass divided by bulk sample volume), and apparent density (wet mass divided by bulk sample volume) by use of CT scan energy specific (linear) relationships (Fig. 1) (Faulkner et al. 1993; Giambini et al. 2015).
To account for the lack of cancellous bone geometry due to the clinical CT resolution, continuum-level FEMs use spatial variations of BMD related to mechanical properties in order to achieve physiologic accuracy. In the development of these FEMs, two relationships are required to convert raw $\mathrm{CT} \mathrm{x}$-ray attenuation data to bone mechanical properties. The first densitometric relationship relates raw CT attenuation to BMD $(\rho=\mathrm{a} * \mathrm{HU}$ $+b)\left(\rho_{\mathrm{QCT}}\right.$ if phantom calibrated), and the second mechanical property relationship, relates BMD to bone mechanical properties. To develop the second relationship, most studies use relationships developed using physical specimens and have found continuous functions and power relationships best fit experimental data $\left(E=\alpha \rho^{\beta}\right)$, where $E$ is the Young's Modulus, $\alpha$ and $\beta$ are experimentally derived parameters, and $\rho$ is the bone density (Helgason et al. 2008). Alternatively, relationships may be piecewise functions that represent experimentally derived relationships for cancellous and cortical bone separately. Density-modulus relationships for cancellous and cortical bone are determined by the experimental method in which they are derived. Small bone sample are typically mechanically tested to derive the desired relationships. Many of these studies test cancellous samples and cortical samples separately (instead of whole bones), and therefore derive separate equations for each bone type (Rice et al. 1988; Schaffler and Burr 1988). Due to the experimental testing of physical specimens, these equations use physical BMD measures such as ash, apparent, or tissue density; and therefore when using QCT derived equivalent density $\left(\rho_{\mathrm{QCT}}\right)$, conversions between $\mathrm{QCT}$, ash $\left(\rho_{\text {ash }}\right)$, apparent $\left(\rho_{\text {app }}\right)$, and tissue densities $\left(\rho_{\text {tissue }}\right)$ are required for accurate FEM development.
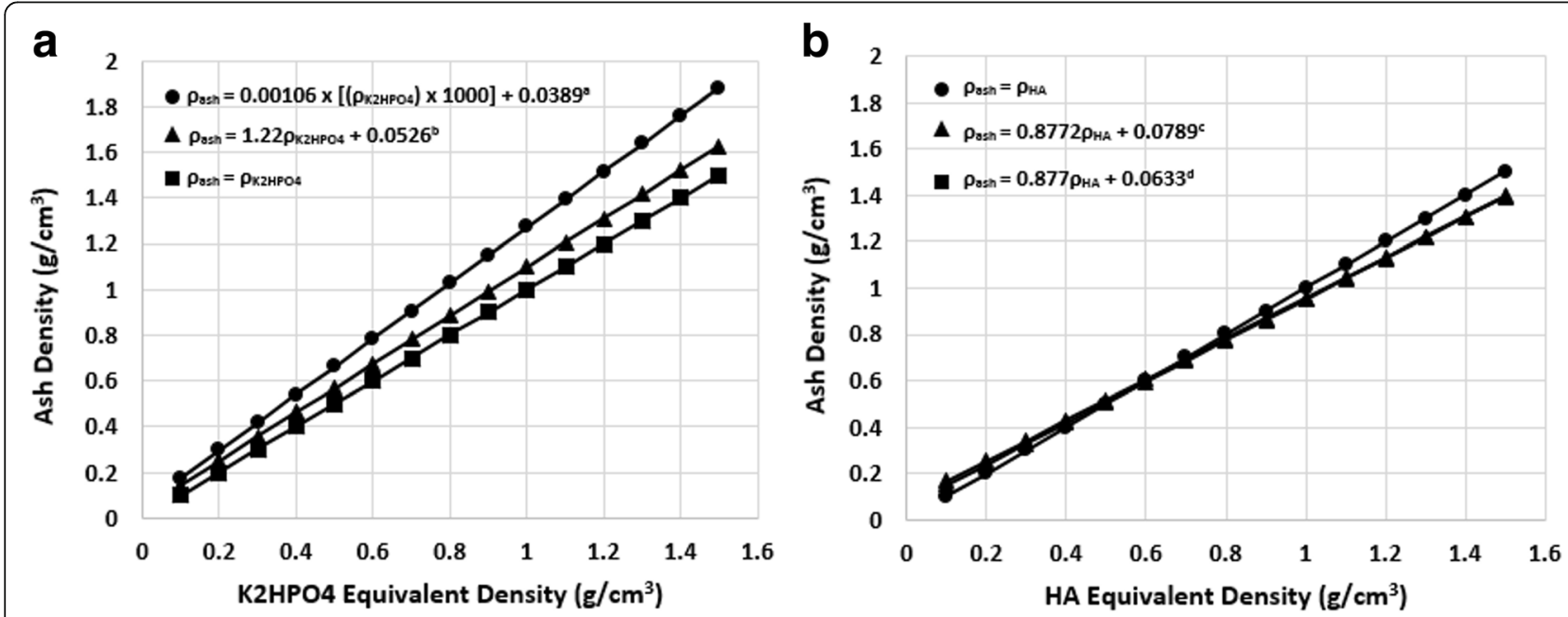

Fig. 1 Ash and QCT equivalent density (a: dipotassium phosphate; b: calcium hydroxyapatite) relationships used in reviewed studies Relationships from: ${ }^{a}$ (Keyak et al. 1994) - 140 kVp, 70 mA; ${ }^{b}$ (Les et al. 1994) - 140 kVp, 30 mA; ${ }^{c}$ Unknown - used in (Eberle et al. 2013a, b); ${ }^{d}$ (Keyak et al. 2005) - 80 kVp, 280 mAs 
Experimentally derived density-modulus relationships are site-specific (Morgan et al. 2003; Schileo et al. 2008), and are also affected by the quality and pathology of the bone, with density being a function of the CT scanner settings (Faulkner et al. 1993). Therefore, the purpose of this literature review is to report i) the relationships used in the conversion of QCT equivalent density $\left(\rho_{\mathrm{QCT}}\right)$ measures to ash $\left(\rho_{\text {ash }}\right)$, apparent $\left(\rho_{\text {app }}\right)$, and/or tissue densities $\left(\rho_{\text {tissue }}\right)$ in recent FE studies, and ii) the combined densitometric and density-modulus relationships impact on FEM accuracy.

\section{Methods}

The specific relationships used in the conversion of QCT $\left(\mathrm{K}_{2} \mathrm{HPO}_{4}\right.$ or $\left.\mathrm{HA}\right)$ to physical density (ash, apparent, or tissue) in current FE studies were reviewed. The search was limited to FE studies of human bone published after January 1st, 2010, reporting clinical scanner image acquisition with use of a calibration phantom. Studies reporting only HR-pQCT or micro-CT scanner image acquisition were omitted. Literature searches included the search terms "finite element analysis, FE, or finite element" with combinations of "quantitative computed tomography," "QCT," and "bone." Included articles represented a variety of calibration phantom types, anatomical locations, CT scanner settings, and density relationships and density-modulus relationships. Each article was carefully reviewed by one of two independent reviewers (NKK \& JMR), and characterized based on anatomical location, density calibration type and manufacturer, scanner, and scanner settings. Articles not reporting any of the above were included as long as they clearly defined use of a calibration phantom with a clinical scanner. All articles were secondly reviewed by a single author (NKK) for completeness, and to extract specific densitometric and density-modulus relationships reported in each study. At this stage, references reported for densitometric and density-modulus relationships were checked and collected. Discrepancies between reported relationships and accurate relationships were noted, and corrected, if possible. Validation metrics and results are included for studies comparing experimental to FEM results.

The number of studies reporting each phantom type (Dipotassium Phosphate $\left(\mathrm{K}_{2} \mathrm{HPO}_{4}\right)$, Hydroxyapatite (HA), both, other, or not reported), were determined along with manufacturer of the phantom. Of the studies reviewed, four relationships were noted (ash density from $\mathrm{K}_{2} \mathrm{HPO}_{4}$ density, ash density from HA density, ash density from CT number, or apparent density from CT number). Studies using these relationships were collected and plotted (Figs. 1 and 2). Density-modulus relationships were tabulated (Table 1), but not reviewed in detail, as this is beyond the scope of this review, and many are summarized in detail in the review by Helgason et al. (2008).

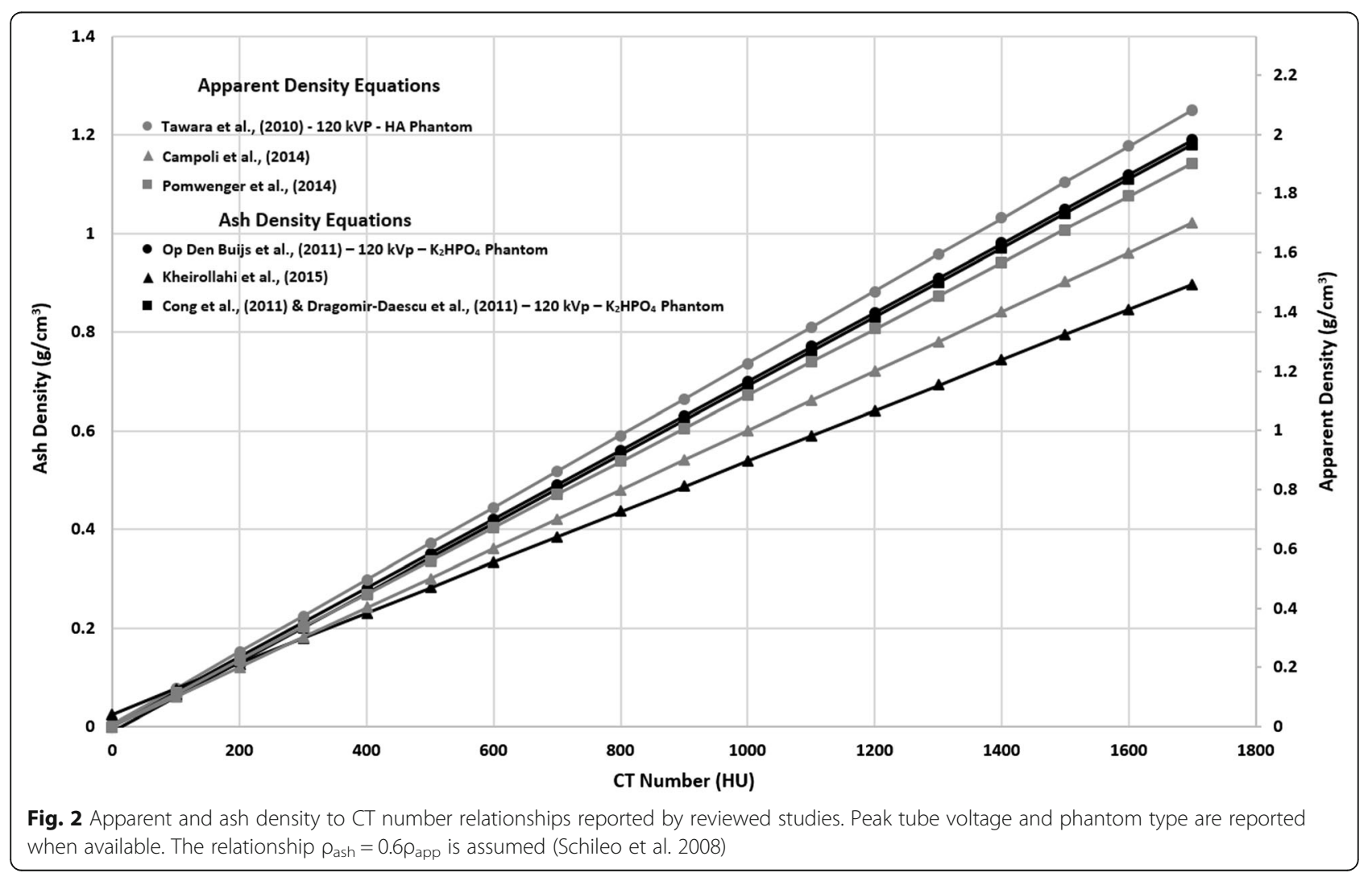




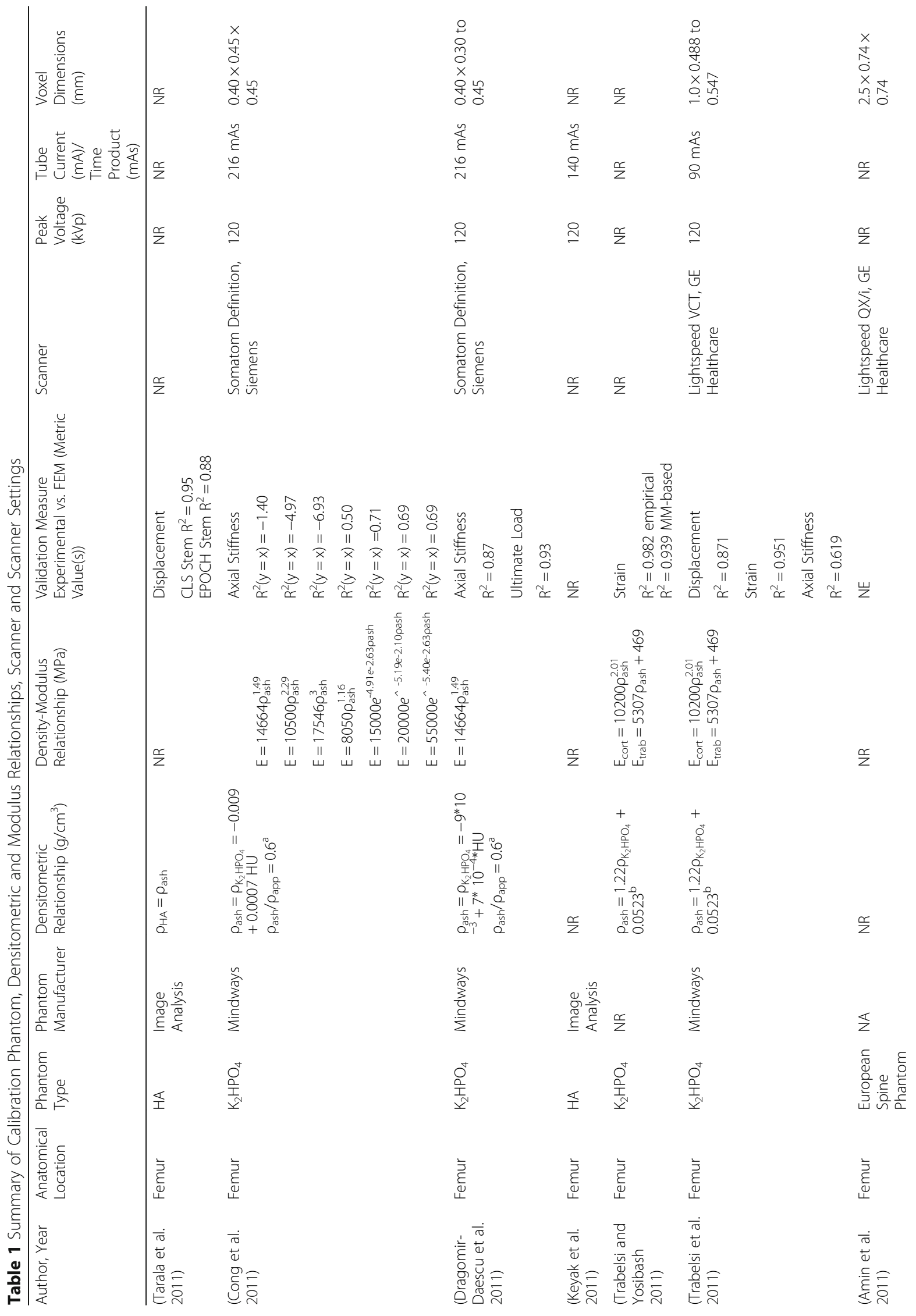




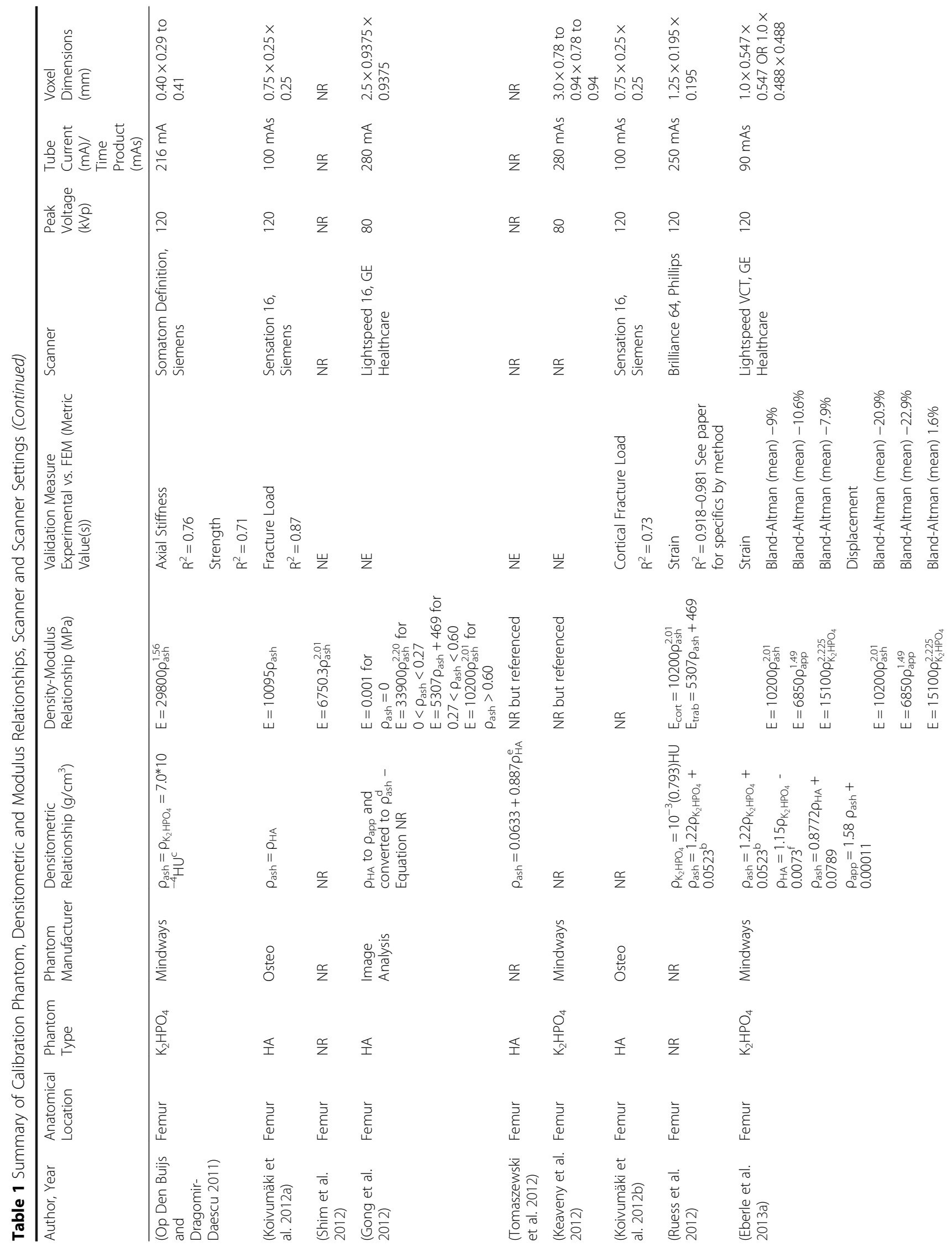




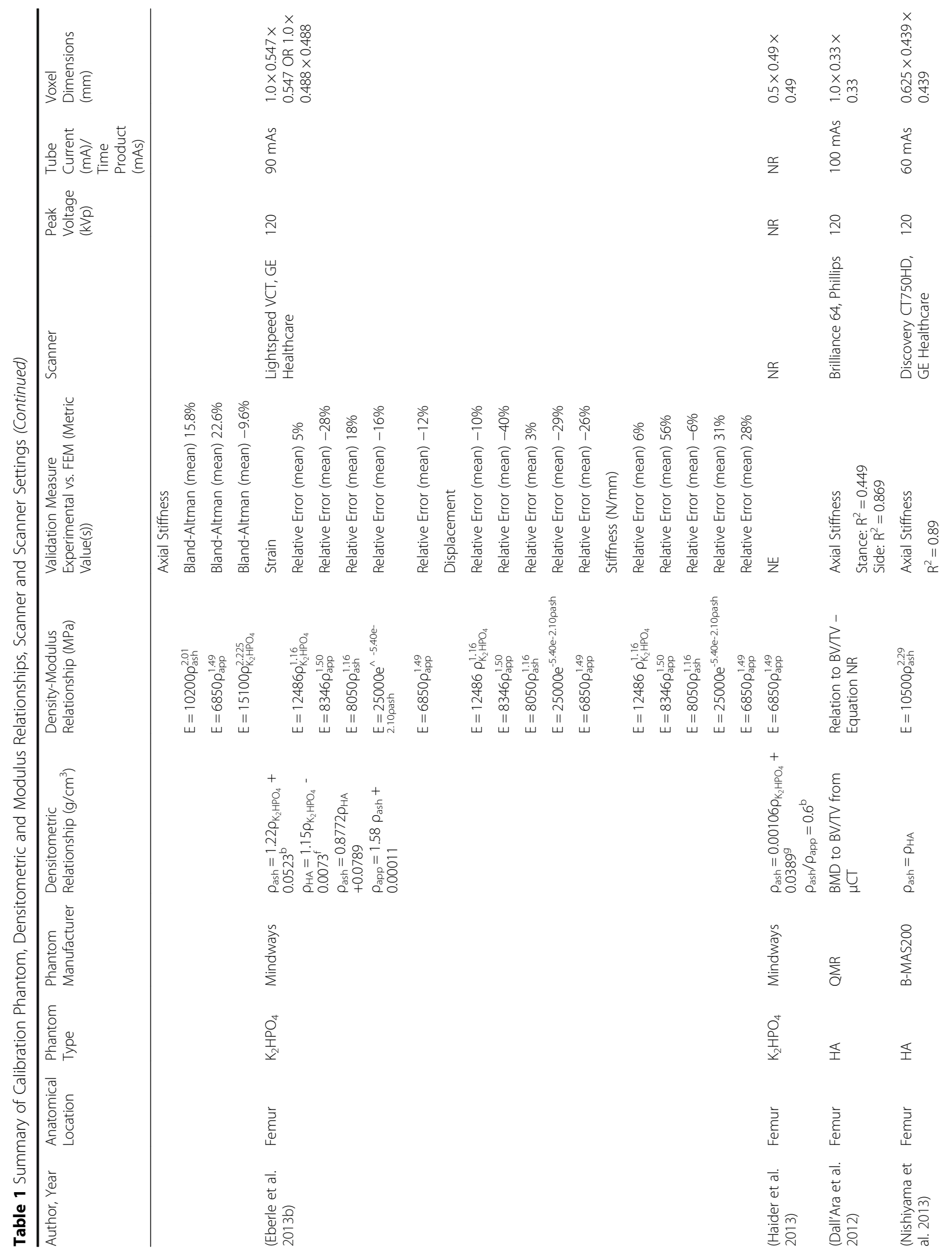




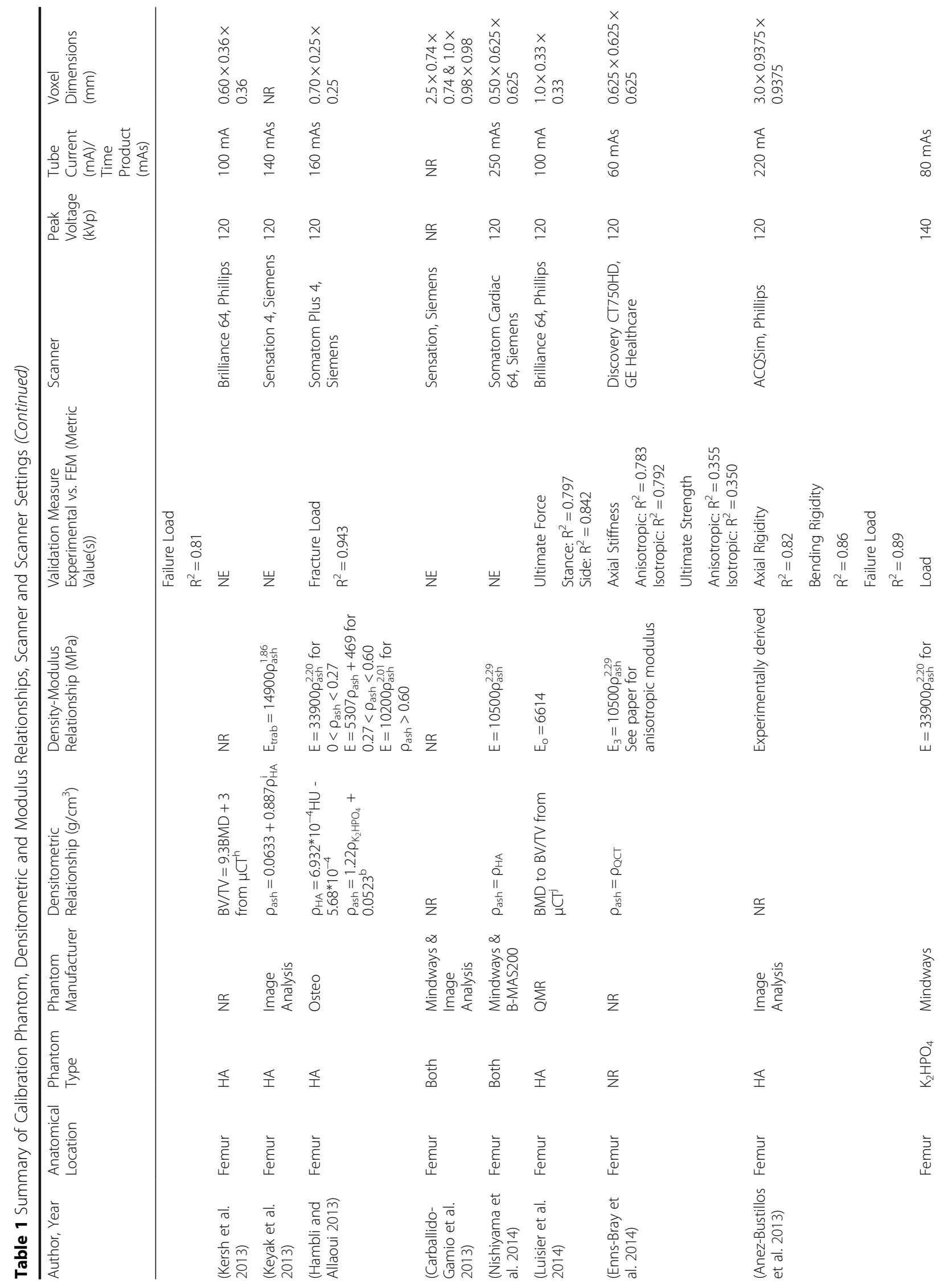


Knowles et al. Journal of Experimental Orthopaedics (2016) 3:36

Page 8 of 16

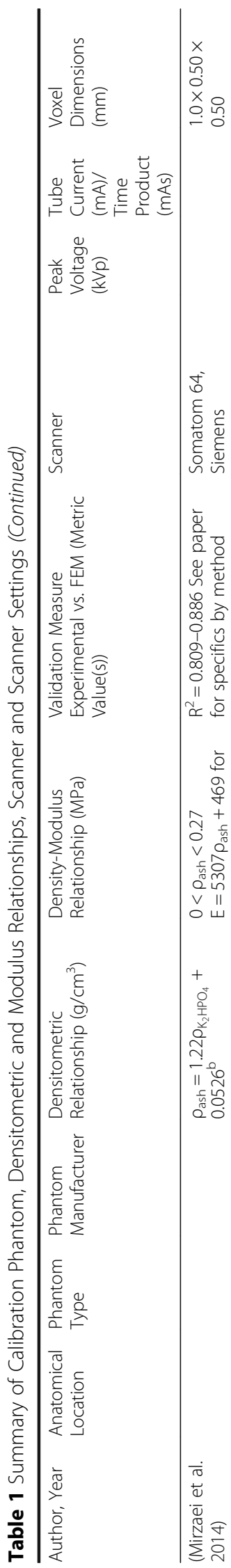

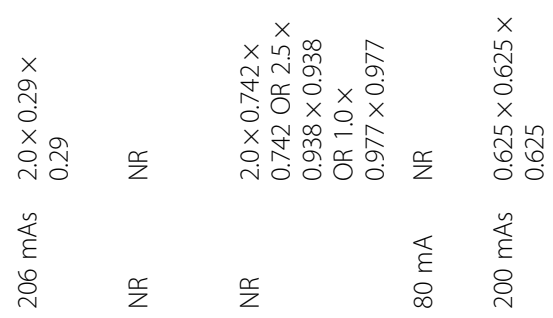

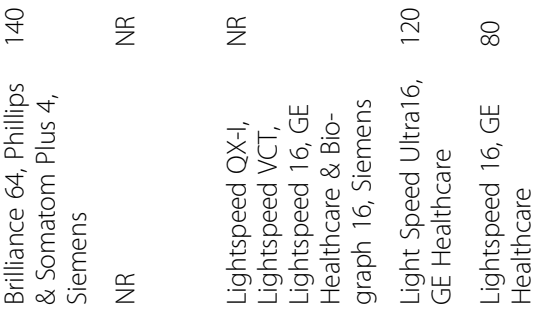

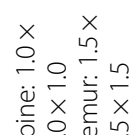

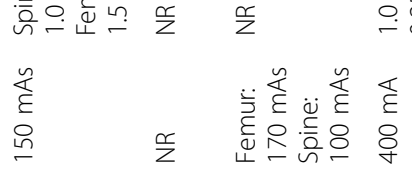

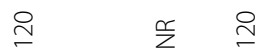

$\stackrel{\frac{c}{z}}{2}$

$\stackrel{Ð}{\simeq}$

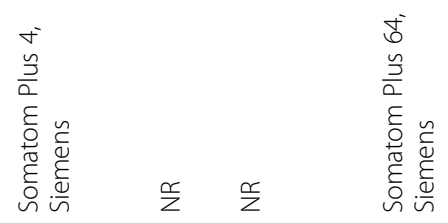

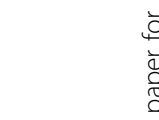

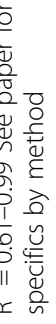

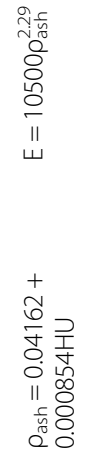

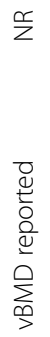

$\frac{\infty}{z} \quad \frac{m}{z}$

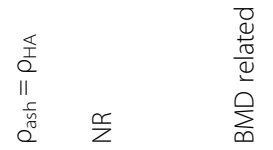

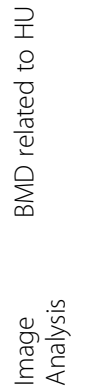

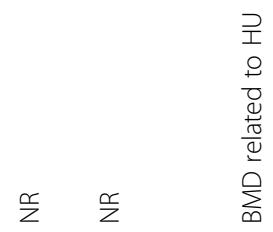

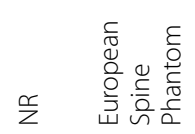

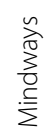

$\sum_{\infty}^{\infty}$

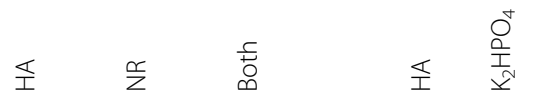

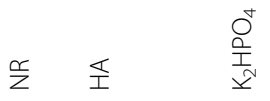

至

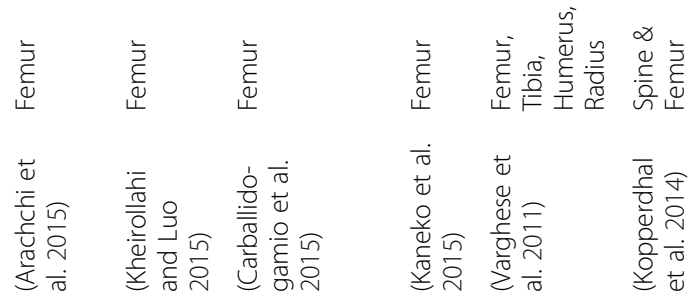

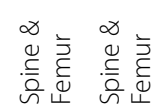

产

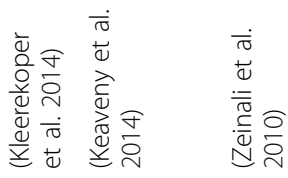

$\stackrel{\frac{\pi}{0}}{n}$ 


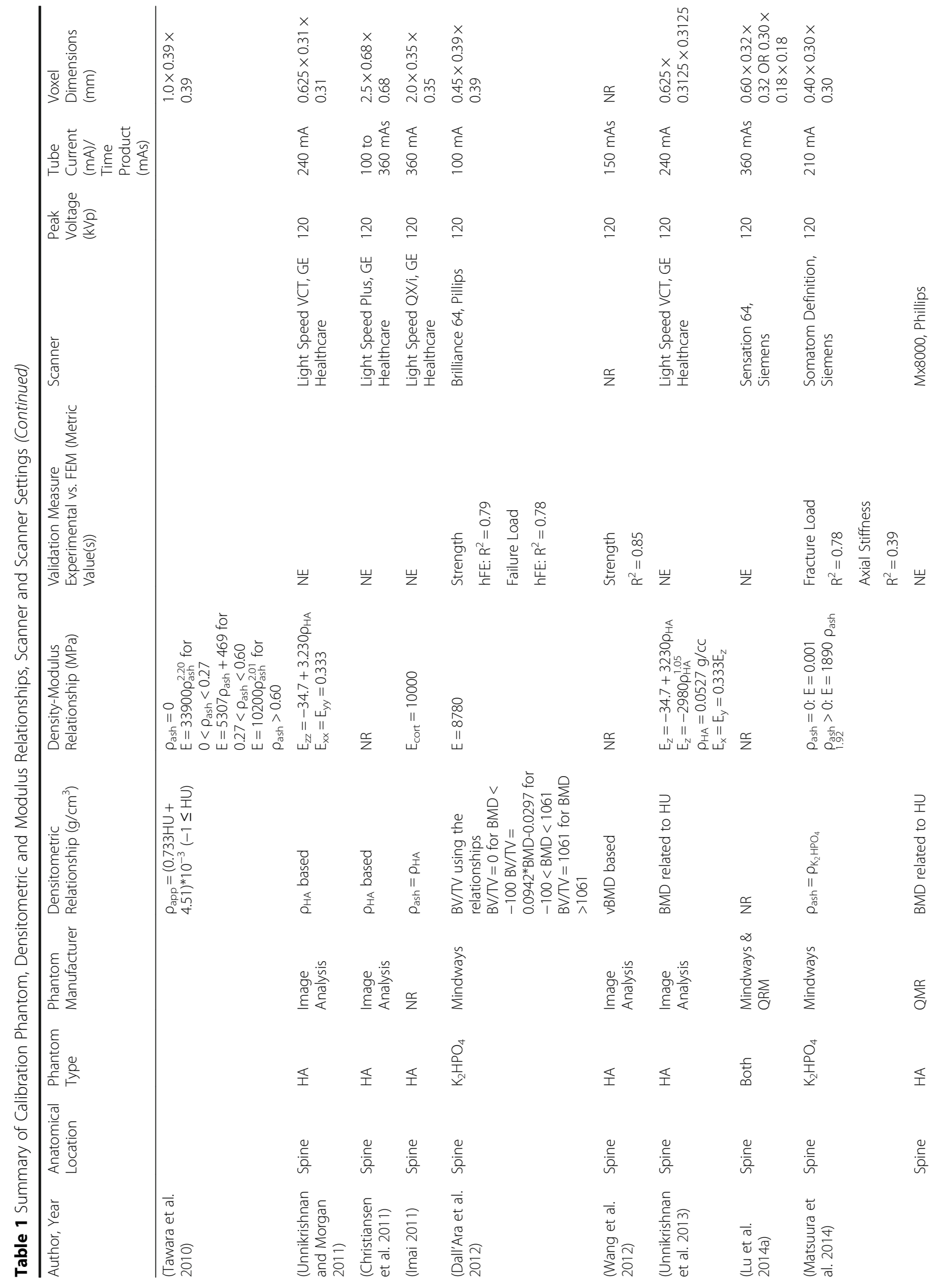


Knowles et al. Journal of Experimental Orthopaedics (2016) 3:36

Page 10 of 16

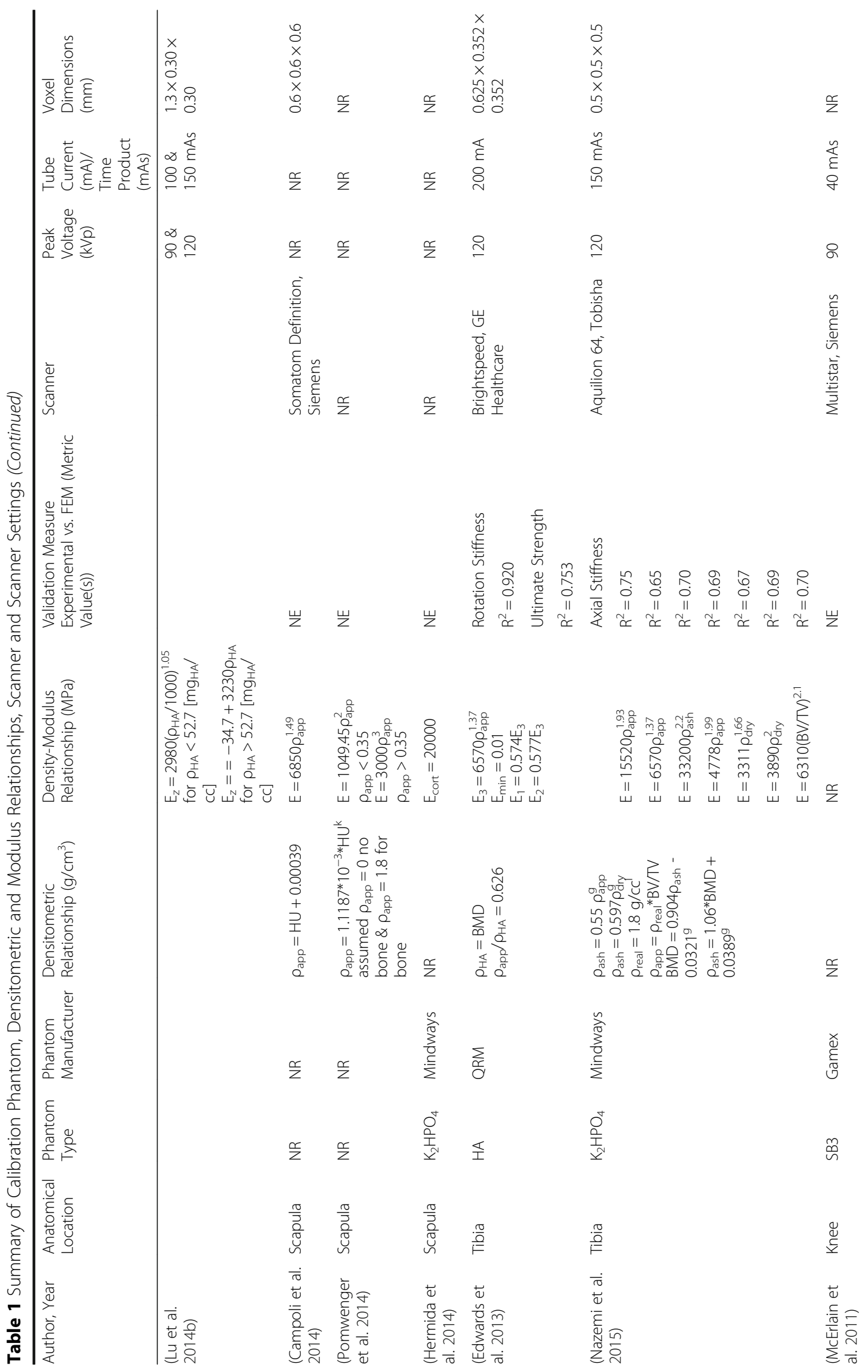




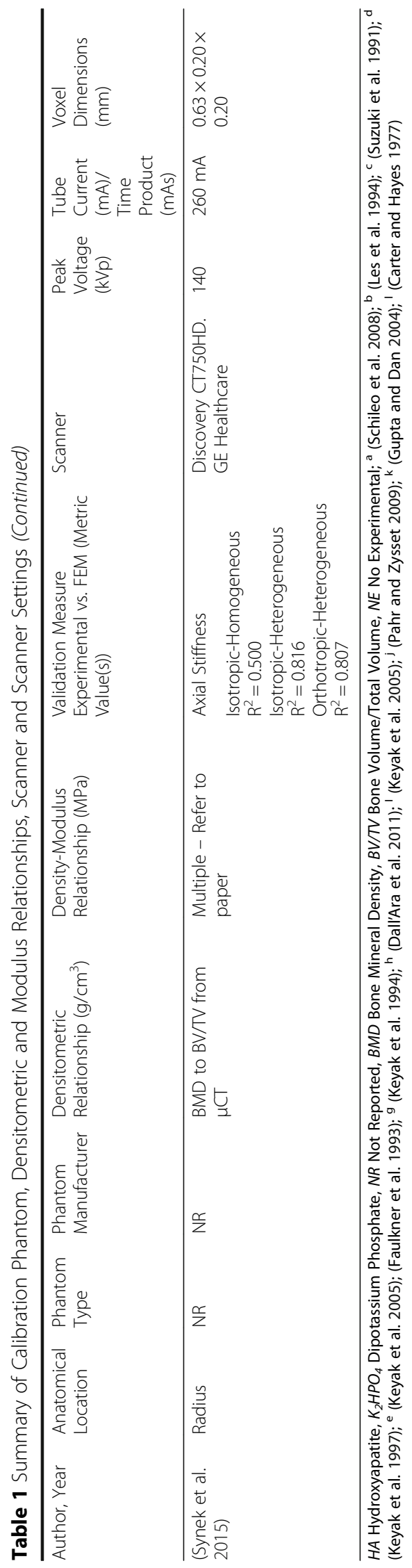




\section{Densitometric measurements Ash density}

Ash density $\left(\rho_{\text {ash }}\right)$ is a measure typically taken on small bone samples, which are used to determine densitymodulus relationships mechanically tested as a continuum (Les et al. 1994). It is calculated as the ash mass divided by bulk sample volume. In the method described by Les et al. (1994), physical measurements were taken on cylindrical bone samples to determine the total sample volume. The sample was ashed in a muffle furnace at $800{ }^{\circ} \mathrm{C}$ for $24 \mathrm{~h}$, and weighed to determine the ash mass and the ash density is calculated by dividing by the sample volume.

A similar study tested the effect of ashing temperature on sample mass. Öhman et al. (2007) found that ashing their samples at a temperature of $650{ }^{\circ} \mathrm{C}$ for $24 \mathrm{~h}$ in a muffle furnace, produced little variation in measured ash mass, compared to increased furnace temperature. Temperatures between 600 and $650{ }^{\circ} \mathrm{C}$, produced significant variation in sample mass. Although the original method described by Les et al. (1994) is still most commonly used, more accurate methods of initial volume measurement, such as micro-CT, or laser scanning may be employed.

\section{Apparent density}

Bone apparent density $\left(\rho_{\text {app }}\right)$ is calculated as the wet mass of a bone tissue sample divided by the total sample volume. To determine wet mass, Galante et al. (1970) first washed samples to remove marrow, immersed samples in distilled water, and degassed under vacuum. Samples were then removed from water, centrifuged for $15 \mathrm{~min}$ at $8000 \times \mathrm{g}$ and suspended from an analytical balance for submerged mass. Samples were removed and blotted dry and weighed in air for wet mass. Similarly, Keyak et al. (1994) measured bone cubes by first defatting samples in an 8 and $16 \mathrm{~h}$ ethyl alcohol bath, followed by an 8 and $16 \mathrm{~h}$ ethyl ether bath. Samples dried for $24 \mathrm{~h}$ at room temperature and were weighed for dry mass. The cubes were rehydrated under vacuum in water for $24 \mathrm{~h}$, centrifuged at $750 \times \mathrm{g}$ for $15 \mathrm{~min}$, and weighed for hydrated mass. Sample apparent density was then calculated with the known cube volume.

\section{Tissue density}

The tissue density $\left(\rho_{\text {tissue }}\right)$ also uses the wet mass of the sample; however, as the name suggests, tissue density is a measure of the physical bone tissue (excluding pores) (Galante et al. 1970). It is calculated by dividing the wet mass by the volume of bone tissue. To determine the volume of bone tissue Galante et al. (1970) calculated the difference between the wet and submerged mass.

\section{Radiological (mineral equivalent) density}

Radiological, or mineral equivalent $\left(\mathrm{K}_{2} \mathrm{HPO}_{4}\right.$ or $\left.\mathrm{HA}\right)$ density $\left(\rho_{\mathrm{K}_{2} \mathrm{HPO}_{4}}, \rho_{\mathrm{HA}}\right.$, or $\left.\rho_{\mathrm{QCT}}\right)$ is calculated by sampling the average CT number $(\mathrm{HU})$ value of all voxels within a region of interest of the known calibration phantom sample rods. The radiographic density of the rods can be estimated using the calibration parameters supplied by the phantom manufacturer, and simple linear regression calculations (Les et al. 1994; Schileo et al. 2008). The QCT calibration can be completed on an entire volume, or by individual CT image.

\section{Results}

Of the 55 studies that met the inclusion criteria and were included, $29 \%$ reported the use of a $\mathrm{K}_{2} \mathrm{HPO}_{4}$ phantom, $47 \%$ an HA phantom, $13 \%$ did not report phantom type, $7 \%$ reported use of both $\mathrm{K}_{2} \mathrm{HPO}_{4}$ and HA phantoms, and $4 \%$ alternate phantom types. The most commonly reported $\mathrm{K}_{2} \mathrm{HPO}_{4}$ phantom was the Mindways Software phantom, and the most commonly reported HA phantom was the Image Analysis phantom. The most common densitometric relationship between ash density and QCT equivalent density was that developed by Les et al. (1994) (13\% of studies). Of all studies, 35\% report density-modulus relationships based on ash density, and $18 \%$ report ash density directly equivalent to QCT density $\left(\mathrm{K}_{2} \mathrm{HPO}_{4}\right.$ or $\left.\mathrm{HA}\right)$. Of the studies included as part of this review, $24 \%$ report density-modulus relationships determined either from micro-CT bone volume/total volume $\left(\mu \mathrm{CT}_{\mathrm{BV} / \mathrm{TV}}\right)$, or relate modulus directly to QCT density, through experimental validation (Zeinali et al. 2010; Christiansen et al. 2011; Unnikrishnan and Morgan 2011; Dall'Ara et al. 2012, 2013; Wang et al. 2012; Anez-Bustillos et al. 2013; Kersh et al. 2013; Unnikrishnan et al. 2013; Luisier et al. 2014; Lu et al. 2014b; Carballido-gamio et al. 2015; Synek et al. 2015). Scanner type and/or settings were omitted or only partially reported in $31 \%$ of studies. Studies involving the femur were most prevalent (37), followed by the spine (14), scapula (3), tibia (3), radius (1), knee (1), and humerus (1).

Of the studies reporting density-modulus relationships and experimental validation metrics, those with the lowest mean \%-difference, lowest relative error, or correlations greater than $90 \%\left(R^{2}>0.90\right), 5$ used relationships based on ash density (Dragomir-Daescu et al. 2011; Trabelsi et al. 2011; Trabelsi and Yosibash 2011; Ruess et al. 2012; Hambli and Allaoui 2013), 3 based on $\mathrm{K}_{2} \mathrm{HPO}_{4}$ calibrated density (Zeinali et al. 2010; Eberle et al. 2013a, b), and 1 based on apparent density (Edwards et al. 2013).

\section{Discussion}

When creating continuum-level finite element models with heterogeneous material distributions, BMD must 
first be extracted from scan data, and then a densitymodulus relationship applied. From the studies reviewed, it is difficult to quantify and isolate the effect of chosen densitometric relationships on experimental versus computational model error because reported results are the combination of two relationships (densitometric and density-modulus). It was therefore the goal of this review to provide the current state of QCT in FE modeling, and provide the most common methods used in the conversion of densitometric measures. When assessing the accuracy of density-modulus relationships developed in previous studies, and comparing experimental to computational results, replication of the density measure and/or accurate conversion between density measures is necessary to reduce inaccuracies and error.

The majority of articles included in this review were studies involving the femur. The hip represents one of the most widely studied joints, and as such, many of the densitometric and density-modulus relationships have been developed using femur specimens. Computational models using femur developed densitometric and density-modulus relationships have shown excellent agreement between experimental models and FEMs (Table 1). This is not the case with other bones/joints that lack relationships specific to each specific anatomical location, or use equations that have been developed using femurs, or femur specimens. Differences between the femur and other bones may reduce the effectiveness of translating these relationships for use in other bones/ joints, especially those that exhibit drastically different loading conditions, or mineralization patterns.

A large number of the studies reviewed reported relationships between QCT derived density and ash or apparent density derived in previous studies (Table 1 \& Figs. 1 and 2). Ash density was used as equivalent to QCT density in $18 \%$ of studies. Schileo et al. (2008) showed that although linearly correlated $\left(R^{2}=0.997\right)$, ash and $Q C T$ density are not equivalent. When using densitometric relationships developed in previous studies, it is important to note that the relationships may be a function of the scanner settings and protocol, as well as the anatomical location and pathology of the bone (Faulkner et al. 1993; Kopperdahl et al. 2002; Schileo et al. 2008; Giambini et al. 2015). All these factors may increase the error when then using previously developed bone density-modulus relationships. Giambini et al. (2015) found that reconstruction kernel, as well as tube voltage, had a significant effect on cortical and cancellous QCT derived CT number (HU). This may indicate that even for scans performed on the same scanner, when scanner settings are altered, there may be significant variations in measured CT number, and consequently, material property assignment.

Direct comparison of QCT derived bone density to modulus has the potential to decrease this error, and may improve the accuracy of subject-specific FE models (Kopperdahl et al. 2002). This method minimizes error arising from densitometric conversion, variations in BMD by anatomical location and pathology of bone, and allows for subject-specific material mapping, and density-modulus relationship development. The desired outcome of the FE model should also be noted in choosing a density measure, as BMD corresponds mainly to ultimate strength or modulus, due to its lack of dependence on bone size.

When modeling bone with use of clinical resolution CT, partial volume effects must be taken into account, as well as the averaging of CT lattice vertices in the generated mesh (Taddei et al. 2004). Micro-CT model generation allows for these effects to be minimized, and for the generation of material assignment based on bone volume and mineral density (Dall'Ara et al. 2011; Zysset et al. 2015). However, the clinical availability and feasibility (Poelert et al. 2013), as well as size restrictions and dose of micro-CT limit its use with patient populations, and with larger bones and joints. Giambini et al. (2015) suggest using dual-energy CT to isolate bone from nonbone constituents within the matrix. This method can be implemented on standard clinical CT scanners and provides an interesting framework for future clinicalbased FE studies; however, may be less desirable to patient populations due to increased dose requirements.

This review is not to suggest that previously developed models using mechanical testing, and physical density measurements are obsolete or suboptimal, but rather to provide the current state of QCT-based FE modeling, and to suggest that considerations in density mapping be carefully explored before model generation - in particular when using previously developed relationships. In subject-specific modeling, it is important to use empirical density-modulus relationships developed for the same anatomical site in order to increase model accuracy (Zadpoor and Weinans 2015). In using previously developed density-modulus relationships, comparing ash to apparent density, Schileo et al. (2008) determined a conversion factor of $\rho_{\text {ash }} / \rho_{\text {app }}=0.6$ be used for both cortical and cancellous bone, to avoid over- or underestimation of density. This equation was the most commonly used conversion between the two density measures in the studies reviewed, with most studies reporting previously determined density-modulus relationships using ash density. While this conversion provides one value for cortical and cancellous bone, the authors report that this conversion was determined using human femur specimens, and that similar conversions should be developed for alternate anatomical locations, as the structural mineralization of the tissue is dependent on anatomical location and pathology of the bone (Schileo et al. 2008).

The limitations of this study are that an in-depth evaluation of the specific effect of densitometric conversions of 
FEM outcomes, and specifics of the density-modulus relationships are not discussed. The combination of these two relationships as a requirement for FEM development means they are not mutually exclusive and the effect of one without the other is therefore difficult to assess. We have provided experimental versus FEM validation metrics to allow for the combination of the two relationships to be assessed based on the type of study (Table 1). Specifics regarding the density-modulus relationships are compared and contrasted in the review by Helgason et al. (2008).

The lack of reported scanning parameters used in QCTbased FE studies has been previously stated (Giambini et al. 2015). Many of the studies included in this review lack one or all of phantom type and manufacturer, density and modulus relationships, as well as scanner type and scanner settings (Table 1). Since the combination of these parameters may alter calculated density and subsequent elastic modulus, we suggest that standardized reporting (see Table 1) should be included in future QCT-based FE studies to facilitate comparison with previous findings, and to ensure that methods are repeatable. This has the potential to improve the accuracy of future FE models. When assessing uncertainty in mechanical property assignments in FE models, Laz et al. (2007) provides an excellent framework, which should be incorporated into both experimental and clinical FE models.

\section{Conclusions}

This review assessed the current state of QCT-based FE modeling with use of clinical scanners. It was found that previously developed relationships vary by anatomical location, scanner type and settings. Reporting of all parameters used when referring to previously developed relationships, or in the development of new relationships, may increase the accuracy and repeatability of future FE models. Furthermore, the specific image processing steps in the conversion of raw attenuation data should be included whenever using QCT methods.

\section{Acknowledgments}

Nikolas Knowles and Jacob Reeves are supported in part by the Natural Sciences and Engineering Research Council of Canada, and in part by Transdisciplinary Bone and Joint Training Awards from the Collaborative Training Program in Musculoskeletal Health Research at the University of Western Ontario.

\section{Funding}

This work was supported in part by a Bone and Joint Institute Catalyst Grant, a Lawson Health Research Institute Internal Research Fund Grant, and the Natural Sciences and Engineering Research Council of Canada.

\section{Authors' contributions}

NK reviewed studies, collected and summarized data, and wrote manuscript. JR reviewed studies, collected data, and edited manuscript. LF edited manuscript. All authors read and approved the final manuscript.

\section{Authors' information}

NK is currently completing his PhD at the University of Western Ontario, with research focusing on computational methods in biomechanics of the shoulder. His Masters research focused on quantifying bone density and morphological variations of the glenoid due to osteoarthritis. Previous and future research has made use of computed tomography data using the principles associated with clinical (and currently micro) CT for use in computational modeling. JR is completing his PhD at the University of Western Ontario. His research focuses on the humerus and aims to characterize bone density variations throughout the bone in order to optimize implant fixation and support. LF is an Assistant Professor at the University of Western Ontario with researching spanning a vast number of disciplines. Much of his previous work has focused on the development of joint motion simulators for the analysis of cadaveric specimens and to assess the resulting kinematics of surgical procedures. More recently, his research has focused on implementing surgical mechatronics and computational methods in upper limb research.

\section{Competing interests}

The authors declare that they have no competing interests.

\section{Ethics approval}

Not applicable.

\section{Author details}

${ }^{1}$ Graduate Program in Biomedical Engineering, The University of Western Ontario, 1151 Richmond St, London, ON, Canada. ${ }^{2}$ Roth|McFarlane Hand and Upper Limb Centre, Surgical Mechatronics Laboratory, St. Josephs Health Care, 268 Grosvenor St, London, ON, Canada. ${ }^{3}$ Collaborative Training Program in Musculoskeletal Health Research, and Bone and Joint Institute, The University of Western Ontario, 1151 Richmond St, London, ON, Canada. ${ }^{4}$ Department of Mechanical and Materials Engineering, The University of Western Ontario, 1151 Richmond St, London, ON, Canada.

Received: 30 September 2016 Accepted: 30 November 2016 Published online: 09 December 2016

\section{References}

Amin S, Kopperdhal DL, Melton $\sqcup$ J et al (2011) Association of hip strength estimates by finite-element analysis with fractures in women and men. J Bone Miner Res 26:1593-1600. doi:10.1002/jbmr.347

Anez-Bustillos L, Derikx LC, Verdonschot N et al (2013) Finite element analysis and CT-based structural rigidity analysis to assess failure load in bones with simulated lytic defects. Bone 58:160-167. doi:10.1016/j.bone.2013.10.009

Arachchi S, Pitto RP, Anderson IA, Shim VB (2015) Analyzing bone remodeling patterns after total hip arthroplasty using quantitative computed tomography and patient-specific 3D computational models. Quant Imaging Med Surg 5:575-582. doi:10.3978/j.issn.2223-4292.2015.08.03

Campoli G, Bolsterlee B, van der Helm F et al (2014) Effects of densitometry, material mapping and load estimation uncertainties on the accuracy of patient-specific finite-element models of the scapula. J R Soc Interface 11: 20131146. doi:10.1098/rsif.2013.1146

Carballido-Gamio J, Harnish R, Saeed I et al (2013) Structural patterns of the proximal femur in relation to age and hip fracture risk in women. Bone 57: 290-299. doi:10.1016/j.bone.2013.08.017

Carballido-gamio J, Bonaretti S, Saeed I et al (2015) Automatic multi-parametric quantification of the proximal femur with quantitative computed tomography. Quant Imaging Med Surg 5:552-568. doi:10.3978/j.issn.2223-4292.2015.08.02

Carter D, Hayes W (1977) The compressive behavior of bone as a two-phase porous structure. J Bone Jt Surg 59(7):954-962

Christiansen BA, Kopperdahl DL, Kiel DP et al (2011) Mechanical contributions of the cortical and trabecular compartments contribute to differences in age-related changes in vertebral body strength in men and women assessed by QCT-based finite element analysis. J Bone Miner Res 26:974-983. doi:10.1002/jbmr.287

Cong A, Den Buijs JO, Dragomir-daescu D (2011) Medical engineering \& physics in situ parameter identification of optimal density - elastic modulus relationships in subject-specific finite element models of the proximal femur. Med Eng Phys 33:164-173. doi:10.1016/j.medengphy.2010.09.018

Dall'Ara E, Varga P, Pahr D, Zysset P (2011) A calibration methodology of QCT BMD for human vertebral body with registered micro-CT images. Med Phys 38:2602-2608. doi:10.1118/1.3582946

Dall'Ara E, Pahr D, Varga P et al (2012) QCT-based finite element models predict human vertebral strength in vitro significantly better than simulated DEXA. Osteoporos Int 23:563-572. doi:10.1007/s00198-011-1568-3 
Dall'Ara E, Luisier B, Schmidt R et al (2013) A nonlinear QCT-based finite element model validation study for the human femur tested in two configurations in vitro. Bone 52:27-38. doi:10.1016/j.bone.2012.09.006

Dragomir-Daescu D, Op Den Buijs J, McEligot S et al (2011) Robust QCT/FEA models of proximal femur stiffness and fracture load during a sideways fall on the hip. Ann Biomed Eng 39:742-755. doi:10.1007/s10439-010-0196-y

Eberle S, Göttlinger M, Augat P (2013a) An investigation to determine if a single validated density - elasticity relationship can be used for subject specific finite element analyses of human long bones. Med Eng Phys 35:875-883. doi:10.1016/j.medengphy.2012.08.022

Eberle S, Göttlinger M, Augat P (2013b) Individual density-elasticity relationships improve accuracy of subject-specific finite element models of human femurs. J Biomech 46:2152-2157. doi:10.1016/j.jbiomech.2013.06.035

Edwards WB, Schnitzer TJ, Troy KL (2013) Torsional stiffness and strength of the proximal tibia are better predicted by finite element models than DXA or QCT. J Biomech 46:1655-1662. doi:10.1016/j.jbiomech.2013.04.016

Engelke K, Libanati C, Fuerst T et al (2013) Advanced CT based in vivo methods for the assessment of bone density, structure, and strength. Curr Osteoporos Rep 11:246-255. doi:10.1007/s11914-013-0147-2

Enns-Bray WS, Owoc JS, Nishiyama KK, Boyd SK (2014) Mapping anisotropy of the proximal femur for enhanced image based finite element analysis. J Biomech 47:3272-3278. doi:10.1016/j.jbiomech.2014.08.020

Faulkner KG, Gluer CC, Grampp S, Genant HK (1993) Cross-calibration of liquid and solid QCT calibration standards: corrections to the UCSF normative data. Osteoporos Int 3:36-42. doi:10.1007/BF01623175

Galante J, Rostoker W, Ray RD (1970) Physical properties of trabecular bone. Calcif Tissue Res 5:236-246. doi:10.1007/BF02017552

Giambini H, Dragomir-Daescu D, Huddleston PM et al (2015) The effect of quantitative computed tomography acquisition protocols on bone mineral density estimation. J Biomech Eng 137:1-6. doi:10.1115/1.4031572

Gong H, Zhang M, Fan Y et al (2012) Relationships between femoral strength evaluated by nonlinear finite element analysis and BMD, material distribution and geometric morphology. Ann Biomed Eng 40:1575-1585. doi:10.1007/ s10439-012-0514-7

Gupta S, Dan P (2004) Bone geometry and mechanical properties of the human scapula using computed tomography data. Trends Biomater Artif Organs 17:61-70

Haider IT, Speirs AD, Frei H (2013) Effect of boundary conditions, impact loading and hydraulic stiffening on femoral fracture strength. J Biomech 46:21152121. doi:10.1016/j.jbiomech.2013.07.004

Hambli R, Allaoui S (2013) A robust 3D finite element simulation of human proximal femur progressive fracture under stance load with experimental validation. Ann Biomed Eng 41:2515-2527. doi:10.1007/s10439-013-0864-9

Helgason B, Perilli E, Schileo E, Taddei F (2008) Mathematical relationships between bone density and mechanical properties: a literature review. Clin Biomech 23:135-146. doi:10.1016/j.clinbiomech.2007.08.024

Hermida JC, Flores-Hernadez C, Hoenecke HR, D'Lima DD. Augmented wedgeshaped glenoid component for the correction of glenoid retroversion: a finite element analysis. Shoulder Elb Surg 23(3):347-354

Imai K (2011) Vertebral fracture risk and alendronate effects on osteoporosis assessed by a computed tomography-based nonlinear finite element method. J Bone Miner Metab 29:645-651. doi:10.1007/s00774-011-0281-9

Kaneko M, Ohnishi I, Bessho M et al (2015) Prediction of proximal femur strength by a quantitative computed tomography-based finite element method -creation of predicted strength data of the proximal femur according to age range in a normal population and analysis of risk factors for hip fracture-. Mod Rheumatol 26:151-155. doi:10.3109/14397595.2015.1046220

Keaveny TM, McClung MR, Wan X et al (2012) Femoral strength in osteoporotic women treated with teriparatide or alendronate. Bone 50:165-170. doi:10. 1016/j.bone.2011.10.002

Keaveny TM, McClung MR, Genant HK et al (2014) Femoral and vertebral strength improvements in postmenopausal women with osteoporosis treated with denosumab. J Bone Miner Res 29:158-165. doi:10.1002/jbmr.2024

Kersh ME, Zysset PK, Pahr DH et al (2013) Measurement of structural anisotropy in femoral trabecular bone using clinical-resolution CT images. J Biomech 46: 2659-2666. doi:10.1016/j.jbiomech.2013.07.047

Keyak JH, Lee IY, Skinner HB (1994) Correlations between orthogonal mechanical properties and density of trabecular bone: use of different densitometric measures. J Biomed Mat Res 28:1329-1336

Keyak JH, Rossi SA, Jones KA, Skinner HB (1997) Prediction of femoral fracture load using automated finite element modelling. J Biomech 31:125-133. doi: 10.1016/S0021-9290(97)00123-1
Keyak JH, Kaneko TS, Tehranzadeh J, Skinner HB (2005) Predicting proximal femoral strength using structural engineering models. Clin Orthop Relat Res 437:219-228. doi:10.1097/01.blo.0000164400.37905.22

Keyak JH, Sigurdsson S, Karlsdottir G et al (2011) Male-female differences in the association between incident hip fracture and proximal femoral strength: a finite element analysis study. Bone 48:1239-1245. doi:10.1016/j.bone.2011.03.682

Keyak JH, Sigurdsson S, Karlsdottir GS et al (2013) Effect of finite element model loading condition on fracture risk assessment in men and women: The AGES-Reykjavik study. Bone 57:18-29. doi:10.1016/j.bone.2013.07.028

Kheirollahi H, Luo Y (2015) Assessment of Hip fracture risk using cross-section strain energy determined by QCT-based finite element modeling. Biomed Res Int. doi:10.1155/2015/413839

Kleerekoper M, Greenspan SL, Lewiecki EM et al (2014) Assessing the effects of teriparatide treatment. J Bone Jt Surg 90:1-9. doi:10.1016/S0021-9355(14)74223-7

Koivumäki JEM, Thevenot J, Pulkkinen P et al (2012a) Ct-based fi nite element models can be used to estimate experimentally measured failure loads in the proximal femur. Bone 50:824-829. doi:10.1016/j.bone.2012.01.012

Koivumäki JEM, Thevenot J, Pulkkinen P et al (2012b) Cortical bone finite element models in the estimation of experimentally measured failure loads in the proximal femur. Bone 51:737-740. doi:10.1016/j.bone.2012.06.026

Kopperdahl DL, Morgan EF, Keaveny TM (2002) Quantitative computed tomography estimates of the mechanical properties of human vertebral trabecular bone. J Orthop Res 20:801-805. doi:10.1016/S0736-0266(01)00185-1

Kopperdhal DL, Aspelund T, Hoffmann PF et al (2014) Assessment of incident spine and Hip fractures in women and men using FEA of $C T$ scans. J Bone Miner Res 29:570-580. doi:10.1016/j.devcel.2010.12.007.Peroxiredoxin

Laz PJ, Stowe JQ, Baldwin MA et al (2007) Incorporating uncertainty in mechanical properties for finite element-based evaluation of bone mechanics. J Biomech 40:2831-2836. doi:10.1016/j.jbiomech.2007.03.013

Les CM, Keyak J, Stover SM et al (1994) Estimation of material properties in the equine metacarpus with use of quantitative computed tomography. Jounral Orthop Res 12:822-833

Lu Y, Engelke K, Glueer C-C et al (2014a) The effect of in situ/in vitro threedimensional quantitative computed tomography image voxel size on the finite element model of human vertebral cancellous bone. Proc Inst Mech Eng Part H J Eng Med 228:1208-1213. doi:10.1177/0954411914558654

Lu Y, Engelke K, Puschel K et al (2014b) Influence of 3D QCT scan protocol on the QCT-based finite element models of human vertebral cancellous bone. Med Eng Phys 36:1069-1073. doi:10.1016/j.medengphy.2014.05.001

Luisier B, Dall'Ara E, Pahr DH (2014) Orthotropic HR-pQCT-based FE models improve strength predictions for stance but not for side-way fall loading compared to isotropic QCT-based FE models of human femurs. J Mech Behav Biomed Mater 32:287-299. doi:10.1016/j.jmbbm.2014.01.006

Matsuura Y, Kuniyoshi K, Suzuki T et al (2014) Accuracy of specimen-specific nonlinear finite element analysis for evaluation of radial diaphysis strength in cadaver material. Comput Methods Biomech Biomed Engin 5842:1-7. doi:10.1080/10255842.2014.974579

McErlain DD, Milner JS, Ivanov TG et al (2011) Subchondral cysts create increased intra-osseous stress in early knee OA: a finite element analysis using simulated lesions. Bone 48:639-646. doi:10.1016/j.bone.2010.11.010

Mirzaei M, Keshavarzian M, Naeini V (2014) Analysis of strength and failure pattern of human proximal femur using quantitative computed tomography (QCT)-based finite element method. Bone 64:108-114. doi:10.1016/j.bone. 2014.04.007

Morgan E, Bayraktar H, Keaveny T (2003) Trabecular bone modulus-density relationships depend on anatomic site. J Biomech 36(7):897-904

Nazemi SM, Amini M, Kontulainen SA et al (2015) Clinical Biomechanics Prediction of local proximal tibial subchondral bone structural stiffness using subject-specific finite element modeling : effect of selected density - modulus relationship. J Clin Biomech 30:703-712. doi:10.1016/j.clinbiomech.2015.05.002

Nishiyama KK, Gilchrist S, Guy P et al (2013) Proximal femur bone strength estimated by a computationally fast finite element analysis in a sideways fall configuration. J Biomech 46:1231-1236. doi:10.1016/j.jbiomech.2013.02.025

Nishiyama KK, Ito M, Harada A, Boyd SK (2014) Classification of women with and without hip fracture based on quantitative computed tomography and finite element analysis. Osteoporos Int 25:619-626. doi:10.1007/s00198-013-2459-6

Öhman C, Baleani M, Perilli E et al (2007) Mechanical testing of cancellous bone from the femoral head: experimental errors due to off-axis measurements. J Biomech 40:2426-2433. doi:10.1016/j.jbiomech.2006.11.020

Op Den Buijs J, Dragomir-Daescu D (2011) Validated finite element models of the proximal femur using two-dimensional projected geometry and bone 
density. Comput Methods Programs Biomed 104:168-174. doi:10.1016/j. cmpb.2010.11.008

Pahr DH, Zysset PK (2009) A comparison of enhanced continuum FE with micro FE models of human vertebral bodies. J Biomech 42:455-462. doi:10.1016/j. jbiomech.2008.11.028

Poelert S, Valstar E, Weinans H, Zadpoor AA (2013) Patient-specific finite element modeling of bones. Proc Inst Mech Eng Part H J Eng Med 227:464-478. doi: 10.1177/0954411912467884

Pomwenger W, Entacher K, Resch H, Schuller-Götzburg P (2014) Need for CTbased bone density modelling in finite element analysis of a shoulder arthroplasty revealed through a novel method for result analysis. Biomed Tech (Berl) 59:421-430. doi:10.1515/bmt-2013-0125

Rice J, Cowin S, Bowman J (1988) On the dependence of the elasticity and strength of cancellous bone on apparent density. J Biomech 21(2):155-168

Ruess M, Tal D, Trabelsi N et al (2012) The finite cell method for bone simulations: verification and validation. Biomech Model Mechanobiol 11:425-437. doi:10.1007/s10237-011-0322-2

Schaffler M, Burr D (1988) Stiffness of compact bone: effects of porosity and density. J Biomech 21(1):13-16

Schileo E, Dall'Ara E, Taddei F (2008) An accurate estimation of bone density improves the accuracy of subject-specific finite element models. J Biomech 41(11):2483-2491

Shim VB, Pitto RP, Anderson IA (2012) Quantitative CT with finite element analysis: towards a predictive tool for bone remodelling around an uncemented tapered stem. Int Orthop 36:1363-1369. doi:10.1007/s00264012-1513-x

Suzuki S, Yamamuro T, Okumura H, Yamamoto I (1991) Quantitative computed tomography: comparative study using different scanners with two calibration phantoms. Br J Radiol 64:1001-1006. doi:10.1259/0007-1285-64-767-1001

Synek A, Chevalier Y, Baumbach SF, Pahr DH (2015) The influence of bone density and anisotropy in finite element models of distal radius fracture osteosynthesis: evaluations and comparison to experiments. J Biomech 48: 4116-4123. doi:10.1016/j.jbiomech.2015.10.012

Taddei F, Pancanti A, Viceconti M (2004) An improved method for the automatic mapping of computed tomography numbers onto finite element models. Med Eng Phys 26:61-69. doi:10.1016/\$1350-4533(03)00138-3

Tarala M, Janssen D, Telka A et al (2011) Experimental versus computational analysis of micromotions at the implant-bone interface. Proc Inst Mech Eng H 225:8-15. doi:10.1243/09544119JEIM825

Tawara D, Sakamoto J, Murakami H et al (2010) Mechanical evaluation by patientspecific finite element analyses demonstrates therapeutic effects for osteoporotic vertebrae. J Mech Behav Biomed Mater 3:31-40. doi:10.1016/j.jmbbm.2009.03.001

Tomaszewski PK, van Diest M, Bulstra SK et al (2012) Numerical analysis of an osseointegrated prosthesis fixation with reduced bone failure risk and periprosthetic bone loss. J Biomech 45:1875-1880. doi:10.1016/j.jbiomech. 2012.05.032

Trabelsi N, Yosibash Z (2011) Patient-specific finite-element analyses of the proximal femur with orthotropic material properties validated by experiments. J Biomech Eng 133:061001. doi:10.1115/1.4004180

Trabelsi N, Yosibash Z, Wutte C et al (2011) Patient-specific finite element analysis of the human femur-A double-blinded biomechanical validation. J Biomech 44:1666-1672. doi:10.1016/j.jbiomech.2011.03.024

Unnikrishnan GU, Morgan EF (2011) A new material mapping procedure for quantitative computed tomography-based, continuum finite element analyses of the vertebra. J Biomech Eng 133:071001. doi:10.1115/1.4004190

Unnikrishnan GU, Barest GD, Berry DB et al (2013) Effect of specimen-specific anisotropic material properties in quantitative computed tomography-based finite element analysis of the vertebra. J Biomech Eng 135:101007-101011. doi:10.1115/1.4025179

Varghese B, Short D, Penmetsa R et al (2011) Computed-tomography-based finite-element models of long bones can accurately capture strain response to bending and torsion. J Biomech 44:1374-1379. doi:10.1016/j.jbiomech. 2010.12.028

Wang X, Sanyal A, Cawthon PM et al (2012) Prediction of New clinical vertebral fractures in elderly men using finite element analysis of $\mathrm{CT}$ scans for the osteoporotic fractures in men (MrOS) research group. J Bone Min Res J Bone Min Res 27:808-816. doi:10.1002/jbmr.1539

Zadpoor AA, Weinans H (2015) Patient-specific bone modeling and analysis: the role of integration and automation in clinical adoption. J Biomech 48:750-760. doi:10.1016/j.jbiomech.2014.12.018
Zeinali A, Hashemi B, Akhlaghpoor S (2010) Noninvasive prediction of vertebral body compressive strength using nonlinear finite element method and an image based technique. Phys Medica 26:88-97. doi:10.1016/j.ejmp.2009.08.002

Zysset P, Qin L, Lang T et al (2015) Clinical use of quantitative computed tomography-based finite element analysis of the hip and spine in the management of osteoporosis in adults: the 2015 ISCD official positions-part II. J Clin Densitom 18:359-392. doi:10.1016/j.jocd.2015.06.011

\section{Submit your manuscript to a SpringerOpen ${ }^{\circ}$ journal and benefit from:}

- Convenient online submission

Rigorous peer review

- Immediate publication on acceptance

- Open access: articles freely available online

- High visibility within the field

- Retaining the copyright to your article

Submit your next manuscript at $\boldsymbol{s p r i n g e r o p e n . c o m ~}$ 